\title{
Predictors of Concomitant Use of Antipsychotics and Stimulants and Its Impact on Stimulant Persistence in Pediatric Attention Deficit Hyperactivity Disorder
}

\author{
Vishal Bali, MS, PhD; Pravin Shivaji Kamble, MS, PhD; and Rajender R. Aparasu, PhD, FAPhA
}

\begin{abstract}
BACKGROUND: Concomitant use of stimulants and atypical antipsychotics is common in pediatric attention deficit hyperactivity disorder (ADHD). However, little is known about the determinants of concomitant use and its utility in the management of pediatric ADHD.
\end{abstract}

OBJECTIVES: To (a) examine predictors of concomitant stimulant and atypical antipsychotic use and (b) evaluate the impact of concomitant atypical antipsychotic use on the persistence of stimulants in children and adolescents diagnosed with ADHD.

METHODS: The retrospective cohort study was conducted using 4 years (January 2004-December 2007) of IMS LifeLink claims data. The study population included children and adolescents aged 6-16 years with a diagnosis of ADHD and those who initiated long-acting stimulants (LAS) from July 2004 to December 2006. Patients were followed for 1 year after index stimulant use. Concomitant use was defined as the concurrent prescription for LAS and atypical antipsychotic agents with at least 14 days overlap after the index LAS claim. Persistence was measured by summing the total number of days a patient remained on the index LAS from the index prescription date with an allowable gap of no more than 30 days. Multiple logistic regression within the conceptual framework of the Andersen Behavioral Model was performed to determine the predictors of concomitant stimulant and atypical antipsychotic use. Multivariate Cox proportional hazards regression within the conceptual framework of the Andersen Behavioral Model was used to examine the impact of concomitant atypical antipsychotic use on persistence of stimulants.

RESULTS: The study cohort consisted of 39,981 children who initiated LAS treatment. Most (96.10\%) received LAS monotherapy, and 3.90\% received LAS and atypical antipsychotic concomitantly. The multiple logistic regression analysis found that gender, health insurance, region, year of cohort entry, season, physician specialty, coexisting mental health conditions, and general mental health status influenced the concomitant use of LAS and atypical antipsychotic agents. Bivariate analyses revealed that concomitant users had longer persistence (by 71 days) than the stimulant-alone users. Cox proportional hazards regression revealed that concomitant atypical antipsychotic was associated with improvement in LAS persistence by $15 \%$ $(\mathrm{HR}=0.85,95 \% \mathrm{Cl}=0.76-0.94)$ in comparison with the LAS recipients who did not use atypical antipsychotic concomitantly. 0ther factors such as age, region, season, coexisting mental health conditions, use of comedications, and general mental health status influenced the LAS treatment persistence among children and adolescents.

CONCLUSIONS: Various predisposing, enabling, and need factors were associated with the concomitant stimulant and atypical antipsychotic use. Concomitant use of atypical antipsychotics was associated with improved LAS treatment persistence in children and adolescents with ADHD.

J Manag Care Spec Pharm. 2015;21(6):486-98

Copyright $\odot 2015$, Academy of Managed Care Pharmacy. All rights reserved.

\section{What is already known about this subject}

Children and adolescents with attention deficit hyperactivity disorder (ADHD) are frequently prescribed antipsychotics to control behavioral symptoms of ADHD or comorbid psychiatric disorders

Psychiatric polypharmacy involving antipsychotics and stimulants has increased in recent years.

\section{What this study adds}

Among children and adolescents with ADHD, 3.90\% concomitantly received LAS and atypical antipsychotics for at least 14 days.

Various predisposing, enabling, and need factors were associated with the concomitant stimulant and atypical antipsychotic use in pediatric ADHD

Addition of atypical antipsychotics to the LAS regimen was associated with improvement in LAS persistence by $15 \%$ among the pediatric ADHD population after controlling for other factors.

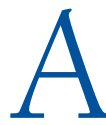

ttention deficit hyperactivity disorder (ADHD) is one of the most common neurobehavioral disorders among children and adolescents, with prevalence rates varying from $2 \%-10 \%$ in the United States. ${ }^{1-3}$ Central nervous system stimulants are the first line of therapy to treat the core symptoms of ADHD-hyperactivity, impulsivity, and inattentiveness-by acting as dopamine agonists in the dopaminergic system. ${ }^{4-6}$ Although nonstimulant alternatives such as atomoxetine are also used in the treatment of ADHD, stimulants, especially long-acting stimulants (LAS), are often used for management of ADHD symptoms due to ease of administration, better adherence, persistence, tolerability, fewer switching and side effects with the treatment, and lesser use of health care services than with the use of intermediate-acting stimulants (IAS) and short-acting stimulants (SAS). ${ }^{7-13}$ The classification of short, intermediate, or long acting is based on half-life of medication and duration of action. ${ }^{14,15}$ The use of other stimulants, such as short or intermediate acting, is influenced by patient needs, costs, and clinical judgment.

Other psychotropic medications, such as antipsychotics, are concomitantly used with stimulants to control ADHD symptoms or its associated comorbidities. ${ }^{16,17}$ Antipsychotics act as dopamine antagonists and show serotonergic 
properties. ${ }^{6,18}$ They are approved by the U.S. Food and Drug Administration (FDA) in children for the treatment of bipolar I disorder (mania or mixed), schizophrenia, and irritability associated with autistic disorder. ${ }^{19-21}$ However, children are being prescribed antipsychotics to control behavioral symptoms of ADHD or comorbid aggression and for other nonapproved indications. ${ }^{6,22,23}$ In addition, psychiatric polypharmacy involving antipsychotics and stimulants has increased in recent years. Cooper et al. (2004) found over a 3-fold increase in the proportion of children who were prescribed antipsychotics for ADHD or conduct disorders from 1996-2001 in the TennCare program. ${ }^{22}$ Fullerton et al. (2012) found that the percentage of ADHD youths taking antipsychotics increased from 8\% in 1996 to $18 \%$ in 2005, which was primarily driven by the increased use of atypical antipsychotics (AAPs). ${ }^{24}$ An analysis of physician visits made by children and adolescents from 1996-2007 revealed significant increase in concomitant prescription of ADHD and antipsychotic medications (adjusted odds ratio $=6.22,95 \%$ confidence interval $[\mathrm{CI}]=2.82-13.70) .{ }^{16}$ Another study examining the prescription of antipsychotics during mental health visits found that approximately 30\%-54\% of these visits by children and adolescents involved coprescription of stimulants. ${ }^{25}$ Existing literature suggests increased risk for adverse effects such as extrapyramidal symptoms, seizures, sedation, obesity, type 2 diabetes mellitus, hyperprolactinemia, gynecomastia, and cerebrovascular or cardiovascular morbidity in children and adolescents using AAPs. ${ }^{6,26-29}$ A recent literature review by the Agency for Healthcare Research and Quality found limited evidence for the effectiveness of secondgeneration antipsychotics in the treatment of ADHD. ${ }^{30}$

Although concomitant use of LAS and AAPs is common in pediatric settings, little is known about the prevalence of and factors associated with concomitant use of LAS and AAPs in youth with ADHD. Recently, Betts et al. (2014) examined the prevalence of concomitant psychotropic medication use in commercially insured children and adolescents with ADHD in the United States to find that AAPs were one of the most commonly prescribed concomitant medications (5.8\%-6.8\%). ${ }^{31}$ Sikirica et al. (2013) evaluated psychotropic concomitant medication (PCM) use in ADHD youth in Europe and found that AAPs were the most commonly used PCMs (4.0\% overall, $28.8 \%$ of PCM users). ${ }^{32}$ Additionally, the number of pre-existing comorbidities and high impairment due to the symptom of anger were important predictors of PCM. ${ }^{32}$ However, none of the studies have looked at the predictors of concomitant use of LAS and AAPs in children and adolescents with ADHD. It is important to determine prevalence of and factors associated with the concomitant use of LAS and AAPs in privately insured children and adolescents with ADHD.

Current clinical evidence and practice guidelines suggest continued use of stimulants until the symptoms of ADHD persist. ${ }^{33}$ Poor persistence with the use of stimulants may lead to suboptimal efficacy, negative long-term outcomes, and increased cost of therapy. ${ }^{34,35}$ Several clinical studies found decrease in persistence of stimulant therapy with the increase in the follow-up period. It varied from 53\%-81\% after 1 year, ${ }^{36,37} 21 \%-70 \%$ at the end of 3 years, ${ }^{34,38,39}$ and $36 \%$ after 5 years. ${ }^{40}$ In retrospective studies, stimulant persistence ranged from $59 \%$ at 4 months to $12 \%-43 \%$ at the end of 1 year. ${ }^{10,13,41-43}$ Antipsychotics might help to improve persistence to stimulant treatment through control of psychiatric comorbidities or behavioral symptoms of ADHD. On the other hand, the use of AAPs might lead to reduced efficacy of stimulants due to their opposite mechanism of action on the dopaminergic system. ${ }^{6,44}$ A study by Sikirica et al. (2012) looked at the treatment patterns, resource utilization, and costs in ADHD children treated with AAPs when compared with non-antipsychotic medications ${ }^{45}$ This study did not find any difference in the persistence of the index stimulant between ADHD children treated with AAPs and and those treated with non-antipsychotics. ${ }^{45}$ However, the impact of the concomitant use of AAPs on the persistence of LAS therapy is largely unknown. This information could help clinicians in improving treatment persistence and subsequent outcomes among ADHD patients. Therefore, the objectives of this study were to (a) determine predictors of concomitant use of LAS and AAPs and (b) examine the impact of concomitant use of AAPs on persistence of LAS treatment regimens in children and adolescents with ADHD.

\section{Methods}

\section{Study Design and Data Source}

This retrospective study used 4 years of claims data (January 2004-December 2007) from IMS LifeLink to achieve the study objectives. IMS LifeLink provides information about commercially insured populations in the United States. It contains information on more than 61 million patients from more than 98 health plans, including enrollment, pharmacy, medical, and institutional claims. Pharmacy data provide information about the claims field for each prescription drug (coded using the National Drug Code [NDC] number), its date of dispensing, quantity dispensed, and the length of supply. Provider and facility claims have information on date of service, diagnostic codes (International Classification of Diseases, Ninth Revision, Clinical Modification [ICD-9-CM] codes), and procedure codes (Current Procedural Terminology, 4th edition, and Healthcare Common Procedure Coding System). All claims in the database include a unique encrypted identifier for each patient to link one file to another.

The standard extract from the Health Plan Claims database consists of 2 files: a claims detail file and an eligibility file. The claims file gives detailed information about patients' pharmacy, medical, and institutional claims. The eligibility file provides data about patients' demographics and enrollment. The data are obtained from multiple sources and undergo a series of quality checks to ensure a standardized format, which is helpful in conducting meaningful comparative analyses. The data are longitudinal in nature with an average member enrollment time of 2.5 years. ${ }^{46}$ This database abides by all Health Insurance Portability and Accountability Act requirements. This study was approved under the exempt category by the Institutional Review Board for the Protection of Human Subjects at the University of Houston. 


\section{Study Population}

The study sample selection process is presented in Figure 1. The study cohort was identified using prescription claims for LAS (methylphenidate, dexmethylphenidate, mixed amphetamine salts, pemoline, and lisdexamfetamine dimesylate) and with at least 1 medical claim with a diagnosis of ADHD (ICD-9-CM code 314.xx) during the study period. ${ }^{8,42,47,48}$ Index date was defined as the first prescription fill date of the first LAS from July 2004-December 2006. Cohort selection was limited to ADHD patients using LAS only because LAS are more frequently used in children and adolescents with ADHD than the other types of stimulants. ${ }^{7-11}$ Index date preceded by a 6-month washout was used to identify new users and avoid selection bias due to prevalent users and also to avoid prevalence bias that might be introduced by pre-exposed cohort members to LAS treatment. ${ }^{49}$ New users were those individuals who had no prescription for any stimulant in the 6 months prior to the index date. Inclusion in the cohort required continuous eligibility 6 months before and 1 year after the index date. Selection of the cohort was limited to children and adolescents aged 6-16 years at the index date, since most of the stimulants are indicated for this age group. ${ }^{23,50}$ All the patients in the final cohort were followed for 1 year from the index date. The final cohort included 39,981 children and adolescents with ADHD who initiated use of LAS from July 1, 2004, to December 31, 2006.

\section{Medication Use Variables}

AAP medications such as clozapine, risperidone, olanzapine, quetiapine, ziprasidone, and aripiprazole were identified by using NDC numbers and generic names during the 1-year period after the index date. Concomitant use of LAS and AAP medications was defined as receipt of both medications together for at least 14 days during the 1-year follow-up period. The concomitant use, or polypharmacy, has been already defined in previous literature as receipt of a second prescription 14 or more days before completion of the first prescription. ${ }^{51}$

Medication persistence can be defined as "the duration of the time from initiation to discontinuation of therapy." 52 Therefore, persistence of index LAS was calculated by summing the number of days the patient remained on index LAS therapy from the index LAS prescription date. The maximum gap of 30 days was allowed between consecutive refills of the index LAS. ${ }^{42}$ When the gap exceeded the permissible limit of 30 days, the treatment episode for the patient was terminated even if the patient was persistent with stimulant therapy at a later stage. The objective of the study was to examine the index LAS persistence in terms of time to discontinuation of the index LAS medication. Switching from one type of preparation within the LAS class was allowed, but switching to another class, such as SAS or IAS, was defined as the discontinuation of the index LAS therapy.

\section{Conceptual Framework}

The Andersen Behavior Model of Health Services Use was used to examine factors associated with the concomitant use of LAS and AAPs and discontinuation of index LAS among

\section{FIGURE 1 Flowchart of Study Sample Selection} and Cohort Development

236,692 received LAS

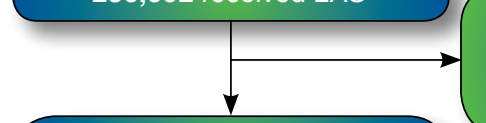

115,824 initiated LAS use from July 1, 2004-December 31, 2006

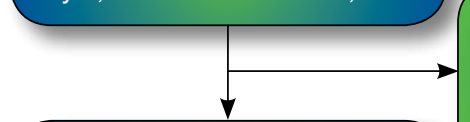

46

46,427 had continuous eligibility 6

months before and 12 months

after the index prescription date

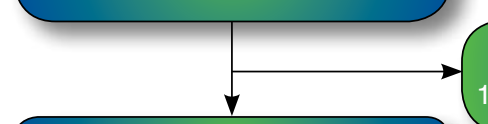

39,981 aged 6 to 16 years

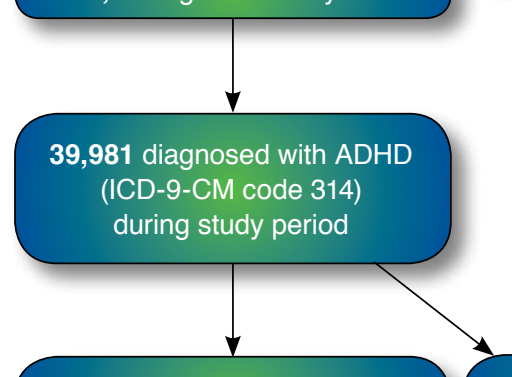

$34,421(96.1 \%)$ received LAS monotherapy

$1,560(3.9 \%)$ received LAS and AAPs (polypharmacy)

AAPS = atypical antipsychotics; $A D H D=$ attention deficit hyperactivity disorder ICD-9-CM=International Classification of Diseases, Ninth Revision, Clinical Modifications; LAS=long-acting stimulants.

children and adolescent diagnosed with ADHD. ${ }^{53}$ This model has been previously used in studies involving medication use. ${ }^{54-56}$ According to this model, health care use is a function of predisposing, enabling, and need factors. Predisposing factors are the characteristics of an individual that exist before the illness and include demographic characteristics, social structure characteristics, and health beliefs. Enabling factors describe the ability of an individual to secure health care services such as income, health insurance, and availability of the service. Need factors reflect perceived and actual health status of an individual. Perceived health status refers to the need for care as perceived by the patient and actual health status refers to the need for care as evaluated by the health care professional.

Predisposing, enabling, and need factors were selected from the existing literature and their availability in the IMS data. ${ }^{6,17,43,57-61}$ Demographic characteristics such as age and gender were used as predisposing factors. Age at the index date (6-12 years and 13-16 years) and gender (male, female) 
TABLE 1 Psychiatric Comorbidities Used in This Study

\begin{tabular}{l|l}
\hline Psychiatric Comorbidities & \multicolumn{1}{c}{ ICD-9-CM Codes } \\
\hline Depression & $296.2,296.3,300.4,309.0,309.1,311 . x x$ \\
\hline Anxiety & $300.0-300.2,313.0,308.3$ \\
\hline Bipolar disorder & $296.0,296.1,296.4,296.5,296.6,296.7,296.8$ \\
\hline Oppositional conduct disorder & 300.3 \\
\hline Obsessive compulsive personality disorder & $301 . x x$ \\
\hline Oppositional defiant disorder & 313.81 \\
\hline Conduct disorder & $312 . x x$ \\
\hline Learning disorders & $315.0-315.3$ \\
\hline Psychosis and pervasive developmental disorders & $290 . x x, 293 . x x, 295 . x x, 297 . x x-299 . x x, 296.24,296.36,296.44,296.54,296.64,296.76,296.84$ \\
\hline Substance abuse and dependence disorders & $291 . x x, 292 . x x, 303 . x x-305 . x x$ \\
\hline Encopresis & $307.6,788.3$ \\
\hline Enuresis & $307.7,787.6$ \\
\hline Tics & $307.2,307.3$ \\
\hline ICD-9-CM = International Classification of Diseases, Ninth Revision, Clinical Modification. \\
\hline
\end{tabular}

were identified from the eligibility and claims files. Enabling factors included type of health coverage (private, public, and other); physician specialty (pediatrics, psychiatry, and other); year of entry into the cohort (2004, 2005, and 2006), as well the season (winter, spring, summer, and autumn) during which the index LAS was prescribed. Need factors included psychiatric comorbidities, psychotropic comedications, and previous mental health-related hospitalization. Psychiatric comorbidities were determined through the presence of a medical claim during the 6-month washout and 1-year follow-up periods for the first objective and until the time to discontinuation of index LAS for the second objective. These comorbidities were depression, anxiety, bipolar disorder, oppositional conduct disorder, obsessive compulsive personality disorder, oppositional defiant disorder, conduct disorder, learning disorders, psychosis and pervasive developmental disorders, substance abuse and dependence, enuresis, encopresis, and tics. The ICD-9-CM codes for these comorbidities are presented in Table 1.8,16,60,62 Recent mental health hospitalization was used as a proxy measure for the severity or general mental health status of the patient. It was defined as an inpatient claim occurring within 180 days of the index date with an ICD-9-CM diagnosis code associated with any mental health disorder (290.xx-319.xx). ${ }^{8,63}$ This approach has been used in past literature dealing with stimulant persistence in ADHD patients and cardiac safety of stimulants in ADHD patients. ${ }^{8,48,64}$ Psychotropic comedications were used as covariates for the second objective only. NDC numbers and generic names were used to identify comedications. Psychiatric comedications were determined through the presence of a prescription claim anytime starting from the index date and until the time to discontinuation of index LAS. Table 2 provides the list of drugs used in this study, which include nonstimulants, alpha 2-agonists, antidepressants, sedatives/hypnotics/anxiolytics, mood stabilizers, and miscellaneous. ${ }^{16,57,60}$ The miscellaneous category represents drugs classes such as anticholinergics (e.g., benztropine), and antiparkinsonian agents (e.g., levodopa). The overlapping claim date was shifted to the end date of the previous claim for patients who refilled their drugs before exhausting the previous supply. ${ }^{65}$

\section{Statistical Analyses}

Data were summarized using descriptive statistics. Statistical differences were assessed using Pearson's $\chi^{2}$ tests for the categorical variables and t-tests for continuous variables. Multiple logistic regression analysis was used to examine factors associated with concomitant use of LAS and AAPs (dichotomized as yes/no). Results were presented as odds ratio (OR) along with 95\% CI for the adjusted analysis. Persistence was analyzed as time to discontinuation of the index LAS from the index prescription date. The Cox proportional-hazards regression model was used to examine the effect of independent variables on the persistence of LAS therapy. Primary independent variable of interest was the use of AAPs, which was modeled as a time varying covariate. Other independent variables, such as sociodemographic characteristics, enabling characteristics, comorbidities, and comedications, were used as control variables and modeled as fixed covariates. Patients were censored if the study period ended without occurrence of the event or discontinuation of index LAS. To measure hazards of discontinuation of LAS therapy, hazard ratios (HR) from Cox proportional hazards model were derived. In the multivariate analysis, proportional hazards assumption for the use of AAPs was checked by including an interaction term between the AAPs and log of time in the adjusted model. Results were presented as HRs along with 95\% CIs for the adjusted analysis. All the analyses were conducted at a priori 5\% alpha level. SAS version 9.2 was used for all the analyses (SAS Institute Inc., Cary, NC).

\section{Results}

Figure 1 presents the development process of the study cohort and sample selection-236,692 children and adolescents received LAS from 2004-2007. Of these children and adolescents, 115,824 initiated LAS use from July 1, 2004, to December 31, 2006. After applying the continuous eligibility 


\begin{tabular}{l|l}
\hline Drug Class & \multicolumn{1}{c}{ Medication } \\
\hline Long-acting stimulants & $\begin{array}{l}\text { Methylphenidate (Ritalin LA, Metadate CD, Concerta, Daytrana) } \\
\text { Dexmethylphenidate (Focalin XR) } \\
\text { Mixed amphetamine salts (Adderall XR, Amphetamine-Dextroamphetamine cap SR 24HR) } \\
\text { Pemoline (generic, Cylert) } \\
\text { Lisdexamfetamine dimesylate (Vyvanse) }\end{array}$ \\
\hline Atypical antipsychotics & Ziprasidone, paliperidone, risperidone, olanzapine, aripiprazole, clozapine, quetiapine \\
\hline Nonstimulants & Atomoxetine \\
\hline Alpha 2-agonists & Clonidine, guanfacine \\
\hline Antidepressants & $\begin{array}{l}\text { Bupropion, tricyclic antidepressants (e.g., desipramine) } \\
\text { Selective serotonin reuptake inhibitors (e.g., fluvoxamine) } \\
\text { Selective norepinephrine reuptake inhibitors (e.g., venlafaxine) } \\
\text { Others (e.g., isocarboxazid) }\end{array}$ \\
\hline Mood stabilizers & Lithium, anticonvulsants (e.g., gabapentine) \\
\hline Sedatives/hypnotics/anxiolytics & $\begin{array}{l}\text { Anxiolytics (e.g., chloral hydrate), beta blockers (e.g., acebutolol), benzodiazepines (e.g., diazepam), antihistamines } \\
\text { (e.g., cetirizine) }\end{array}$ \\
\hline Miscellaneous & Anticholinergics (e.g., benztropine), antiparkinsonian agents (e.g., levodopa)
\end{tabular}

criteria of 6 months before and 12 months after the index date, 46,427 patients were obtained. Out of these, 39,981 patients were aged 6-16 years and constituted the study cohort. Among the study cohort, 1,560 (3.9\%) concomitantly received LAS and AAPs for at least 14 days, whereas 38,421 patients (96.1\%) did not receive LAS and AAPs concomitantly for at least 14 days. Table 3 provides sociodemographic and clinical characteristics of patients who initiated ADHD treatment with LAS. Most of the study population who used LAS and AAPs concomitantly were male (73.0\%), aged 6-12 years (60.3\%), privately insured (93.3\%), and lived in the Midwest region (53.1\%). As shown in Table 4, on average, concomitant users had longer persistence (by 71 days) than the users of stimulants alone.

Table 5 presents predictors of concomitant use of LAS and AAPs among children and adolescents who initiated LAS treatment. Boys were 38\% more likely to receive LAS and AAPs concomitantly than girls. Odds of concomitant use of LAS and AAPs were 63\% lower among publicly insured youth than among others. Geographical variation was present in the concomitant use of LAS and AAPs. ADHD youth residing in the Midwest and West were less likely to receive LAS and AAPs concomitantly than those residing in the East. In addition, there was also variation due to year of cohort entry and season during which index LAS had been started. Children and adolescents with ADHD who entered the cohort in 2005 and 2006 were more likely to be prescribed LAS and AAPs concomitantly compared with those who entered the cohort in 2004. Children initiating LAS use in the summer were more likely to receive LAS and AAPs concomitantly, whereas those initiating LAS use in the spring were less likely to receive LAS and AAPs concomitantly than their counterparts. Diagnosis of various comorbidities such as depression; anxiety; bipolar disorder; obsessive compulsive personality disorder; oppositional defiant disorder; conduct disorder, psychosis; and pervasive developmental disorders, enuresis, tics, and mental health-related hospital visits in the past 6 months were positively associated with the concomitant use of LAS and atypical antipsychotic therapy.
Table 6 presents factors associated with LAS treatment persistence in children and adolescents diagnosed with ADHD. Use of AAPs was associated with improvement in LAS persistence by $15 \%(\mathrm{HR}=0.85,95 \% \mathrm{CI}=0.76-0.94)$ when compared with those who used LAS only. Children aged 6-12 years were $26 \%$ more likely to be persistent than those aged 13-16 years. Geographic and seasonal variations were present in the LAS treatment persistence. ADHD patients living in the Midwest were 9\% more likely to be persistent in the use of LAS than those living in the East. ADHD patients living in the South were $22 \%$ less likely to be persistent in the use of LAS than those living in the East. ADHD children initiating LAS use in the winter were $20 \%$ more likely to be persistent in the use of LAS, whereas children initiating LAS use in the summer were $20 \%$ less likely to be persistent in the use of LAS, when compared with the children initiating LAS use in autumn. ADHD patients seeking care from pediatricians were $4 \%$ more likely to use LAS persistently than the others.

With respect to psychiatric comorbidities, depression, anxiety, oppositional conduct disorder, oppositional defiant disorder, conduct disorder, learning disorder, psychosis, pervasive developmental disorders, substance abuse and dependence disorders, and enuresis were positively associated with LAS treatment persistence in children and adolescents with ADHD. Addition of psychotropic medications such as nonstimulants, alpha 2-agonists, antidepressants, mood stabilizers, sedatives/ hypnotics/anxiolytics, and other miscellaneous medications were positively associated with LAS treatment persistence in children and adolescents with ADHD. Recent mental healthrelated hospitalization was negatively associated with LAS treatment persistence in children and adolescents with ADHD.

\section{Discussion}

Little is known about factors associated with concomitant use of LAS and AAPs and its impact on the persistence of LAS use in children and adolescents with ADHD, especially in nonMedicaid populations. In the present study, approximately $4 \%$ 


\section{Predictors of Concomitant Use of Antipsychotics and Stimulants and Its Impact on Stimulant Persistence in Pediatric Attention Deficit Hyperactivity Disorder}

TABLE 3 Characteristics of Children and Adolescents Who Initiated ADHD Treatment with LAS

\begin{tabular}{|c|c|c|c|c|c|c|c|}
\hline \multirow{2}{*}{ Characteristics } & \multicolumn{2}{|c|}{$\begin{array}{c}\text { Overall } \\
(\mathrm{N}=39,981) \mathrm{n}(\%)\end{array}$} & \multicolumn{2}{|c|}{$\begin{array}{l}\text { Polypharmacy } \\
(\mathrm{n}=1,560) \mathrm{n}(\%)\end{array}$} & \multicolumn{2}{|c|}{$\begin{array}{c}\text { Monotherapy } \\
(\mathrm{n}=38,421) \mathrm{n}(\%)\end{array}$} & \multirow[t]{2}{*}{$P$ Value } \\
\hline \multirow{2}{*}{\multicolumn{8}{|c|}{ Predisposing Factors }} \\
\hline & & & & & & & \\
\hline Male & 28,092 & $(70.3)$ & 1,139 & $(73.0)$ & 26,953 & $(70.2)$ & 0.0154 \\
\hline \multicolumn{8}{|l|}{ Age $($ mean $=10.80 \pm 3.06)$} \\
\hline $6-12$ & 26,931 & $(67.4)$ & 940 & $(60.3)$ & 25,991 & $(67.6)$ & $<0.0001$ \\
\hline $13-16$ & 13,050 & $(32.6)$ & 620 & (39.7) & 12,430 & $(32.4)$ & \\
\hline \multicolumn{8}{|c|}{ Enabling Factors } \\
\hline \multicolumn{8}{|l|}{ Health insurance } \\
\hline Private & 37,512 & $(93.8)$ & 1,456 & $(93.3)$ & 36,056 & $(93.8)$ & $<0.0001$ \\
\hline Public & 1,205 & $(3.0)$ & 30 & (1.9) & 1,175 & $(3.1)$ & \\
\hline Other/unknown & 1,264 & $(3.2)$ & 74 & $(4.8)$ & 1,190 & $(3.1)$ & \\
\hline \multicolumn{8}{|l|}{ Region } \\
\hline East & 6,780 & $(17.0)$ & 327 & $(21.0)$ & 6,543 & $(16.8)$ & $<0.0001$ \\
\hline Midwest & 19,640 & $(49.1)$ & 828 & $(53.1)$ & 18,812 & $(49.0)$ & \\
\hline South & 8,913 & $(22.3)$ & 247 & (15.8) & 8,666 & $(22.6)$ & \\
\hline West & 4,648 & $(11.6)$ & 158 & $(10.1)$ & 4,490 & $(11.6)$ & \\
\hline \multicolumn{8}{|l|}{ Year of entry } \\
\hline 2004 & 7,949 & $(19.9)$ & 278 & $(17.8)$ & 7,671 & $(19.9)$ & 0.0616 \\
\hline 2005 & 15,708 & (39.3) & 648 & $(41.6)$ & 15,060 & $(39.2)$ & \\
\hline 2006 & 16,324 & $(40.8)$ & 634 & $(40.6)$ & 15,690 & $(40.9)$ & \\
\hline \multicolumn{8}{|l|}{ Season of index prescription } \\
\hline Winter & 10,592 & $(26.5)$ & 394 & $(25.3)$ & 10,198 & $(26.5)$ & $<0.0001$ \\
\hline Spring & 7,431 & $(18.6)$ & 258 & $(16.5)$ & 7,173 & $(18.7)$ & \\
\hline Summer & 7,744 & $(19.4)$ & 380 & $(24.4)$ & 7,364 & $(19.2)$ & \\
\hline Autumn & 14,214 & $(35.6)$ & 528 & $(33.8)$ & 13,686 & $(35.6)$ & \\
\hline \multicolumn{8}{|l|}{ Physician specialty } \\
\hline Pediatrician & 16,103 & $(40.3)$ & 223 & $(14.3)$ & 15,880 & $(41.3)$ & $<0.0001$ \\
\hline Psychiatrist & 4,993 & $(12.5)$ & 565 & $(36.2)$ & 4,428 & $(11.5)$ & \\
\hline Other & 18,885 & $(47.2)$ & 772 & $(49.5)$ & 18,113 & $(47.2)$ & \\
\hline \multicolumn{8}{|c|}{ Need Factors } \\
\hline \multicolumn{8}{|l|}{ Comorbidities } \\
\hline Depression & 5,408 & $(13.5)$ & 565 & $(36.2)$ & 4,843 & $(12.6)$ & $<0.0001$ \\
\hline Anxiety & 3,709 & $(9.3)$ & 345 & $(22.1)$ & 3,364 & $(8.8)$ & $<0.0001$ \\
\hline Bipolar disorder & 1,223 & $(3.1)$ & 486 & $(31.2)$ & 737 & $(1.9)$ & $<0.0001$ \\
\hline Oppositional conduct disorder & 572 & $(1.4)$ & 78 & $(5.0)$ & 494 & $(1.3)$ & $<0.0001$ \\
\hline Obsessive compulsive personality disorder & 246 & $(0.6)$ & 65 & $(4.2)$ & 181 & $(0.5)$ & $<0.0001$ \\
\hline Oppositional defiant disorder & 3,074 & $(7.7)$ & 505 & $(32.4)$ & 2,569 & $(6.7)$ & $<0.0001$ \\
\hline Conduct disorder & 2,959 & $(7.4)$ & 385 & $(24.7)$ & 2,574 & $(6.7)$ & $<0.0001$ \\
\hline Learning disorders & 1,706 & $(4.3)$ & 77 & $(4.9)$ & 1,629 & $(4.2)$ & 0.1824 \\
\hline Psychosis and pervasive developmental disorders & 1,471 & $(3.7)$ & 348 & $(22.3)$ & 1,123 & $(2.9)$ & $<0.0001$ \\
\hline Substance abuse and dependence disorders & 828 & $(2.1)$ & 101 & $(6.5)$ & 727 & $(1.9)$ & $<0.0001$ \\
\hline Enuresis & 1,063 & $(2.7)$ & 78 & $(5.0)$ & 985 & $(2.6)$ & $<0.0001$ \\
\hline Encopresis & 282 & $(0.7)$ & 24 & $(1.5)$ & 258 & $(0.7)$ & $<0.0001$ \\
\hline Tics & 526 & $(1.3)$ & 60 & (3.9) & 466 & $(1.2)$ & $<0.0001$ \\
\hline \multicolumn{8}{|l|}{ Comedications } \\
\hline Nonstimulants & 3,127 & $(7.8)$ & 175 & $(11.2)$ & 2,952 & $(7.7)$ & $<0.0001$ \\
\hline Alpha 2-agonists & 3,352 & $(8.4)$ & 440 & $(28.2)$ & 2,912 & $(7.6)$ & $<0.0001$ \\
\hline Antidepressants & 5,969 & $(14.9)$ & 736 & $(47.2)$ & 5,233 & $(13.6)$ & $<0.0001$ \\
\hline Mood stabilizers & 761 & (1.9) & 222 & $(14.2)$ & 539 & $(1.4)$ & $<0.0001$ \\
\hline Sedatives/hypnotics/anxiolytics & 5,875 & $(14.7)$ & 303 & $(19.4)$ & 5,572 & $(14.5)$ & $<0.0001$ \\
\hline Miscellaneous & 129 & $(0.3)$ & 33 & $(2.1)$ & 96 & $(0.3)$ & $<0.0001$ \\
\hline Recent mental health-related hospitalization & 439 & $(1.1)$ & 158 & $(10.1)$ & 281 & $(0.7)$ & $<0.0001$ \\
\hline
\end{tabular}




\begin{tabular}{|c|c|c|c|c|}
\hline \multirow[t]{3}{*}{ TABL } & \multicolumn{4}{|c|}{$\begin{array}{l}\text { Mean and Median Treatment } \\
\text { Duration in Children and } \\
\text { Adolescents Initiating LAS }\end{array}$} \\
\hline & \multicolumn{2}{|c|}{ Polypharmacy Users } & \multicolumn{2}{|c|}{ Monotherapy Users } \\
\hline & $\operatorname{Mean}^{\mathrm{a}}(95 \% \mathrm{CI})$ & Median & $\operatorname{Mean}^{\mathrm{a}}(95 \% \mathrm{CI})$ & Median \\
\hline Persistence & $\begin{array}{l}225.7 \pm 132.6 \\
(219.1-232.3)\end{array}$ & 245.5 & $\begin{array}{l}154.6 \pm 129.1 \\
(153.3-155.9)\end{array}$ & 105.0 \\
\hline
\end{tabular}

aSignificant mean difference in treatment duration between polypharmacy and monotherapy users at $P<0.0001$

$C I=$ confidence interval; $L A S=$ long-acting stimulants.

of commercially insured children and adolescents with ADHD concurrently received LAS and AAPs. This rate is similar to a recent study that found that $5.8 \%-6.8 \%$ of commercially insured children and adolescents in the United States with ADHD concurrently received AAPs. ${ }^{31}$ Another study from Europe found that $4.0 \%$ of the ADHD patients using ADHD medications also received AAPs. ${ }^{32}$

This study found that various predisposing, enabling, and need factors were associated with the concomitant stimulant and AAP use and LAS treatment persistence. Among predisposing factors, boys were more likely to receive LAS and AAPs concomitantly than girls. This finding is consistent with the previous literature and could be attributed to behavioral symptoms of ADHD among boys. ${ }^{7,8,10,42,43,66,67}$ Various enabling factors such as region, year of cohort entry in the study, season of index LAS prescription, physician specialty, and health insurance coverage were important predictors of concomitant use of LAS and AAPs. When compared with the eastern region, ADHD youth residing in other regions had a lower likelihood of concomitant use of LAS and AAPs. A previous study attributed geographical differences in identification and treatment of ADHD to the number, age, and type of physicians. This could also be due to differences in learning, training, and practice culture among the physicians and patient case mix. ${ }^{68}$ Other possible reasons for regional differences in the concomitant use of LAS and AAPs could be the socioeconomic status of the ADHD population, different controlled substance laws in different states, anti-Ritalin campaigns, direct-to-consumer advertising, perceptions, and expectations of caregivers about medication use. ${ }^{69}$

Pediatricians in the present study were less likely to prescribe LAS and AAPs concomitantly, whereas psychiatrists were more likely to prescribe LAS and AAPs concomitantly. Past studies indicate physician specialty to be an important predictor of concomitant psychotropic medication use in children and adolescents. ${ }^{16,17,70}$ This is possible because psychiatrists frequently see more treatment-resistant patients who have failed standard treatment and, thus, need concomitant therapy to treat ADHD. Likelihood of concomitant use of LAS and AAPs was $32 \%$ higher in 2005 and then decreased to $20 \%$ in 2006. In November 2005, the FDA issued a black box warning against the use of AAPs. ${ }^{71,72}$ General concerns regarding use of potent antipsychotics in the pediatric population, coupled with the black box warning, might have cautioned physicians against the concomitant use with stimulants in this vulnerable population.

ADHD patients with public health insurance were less likely to receive LAS and AAPs concomitantly. Previous studies have reported a mixed relationship between health insurance and concomitant use of LAS and AAPs. Some studies have found higher rates of receipt of multiclass psychotropic medications among privately insured youth, ${ }^{16,17,73}$ whereas another study has found this rate to be higher in publicly insured youth. ${ }^{19}$ These mixed findings could be due to the methodological differences in capturing concomitant use, study populations, and study settings. Future research should examine the differential impact of health insurance, if any, on the concurrent use of LAS and AAPs in the pediatric population.

Among need factors, diagnosis of any comorbidity and recent mental health-related hospitalizations were positively associated with concomitant use of LAS and AAPs. In fact, diagnosis of bipolar disorder, psychosis, and pervasive developmental disorders were the main drivers of concomitant use of LAS and AAPs in youth with ADHD. Patients diagnosed with bipolar disorder, psychosis, and pervasive developmental disorders were 3 to 9 times more likely to receive LAS and AAPs concomitantly than patients without these comorbidities. This is consistent with a recently published study that found that number of pre-existing comorbidities was an important predictor of psychotropic concomitant medication use. ${ }^{32}$ Treatment of ADHD is challenging due to the complexity of the disease and associated psychiatric comorbidities. ${ }^{74,75}$ Treatment of ADHD in the presence of psychiatric comorbidities varies by type of comorbidity. ${ }^{75,76}$ Various AAPs are approved by the FDA for the treatment of bipolar I disorder (mania or mixed), schizophrenia, and irritability associated with autistic disorder. ${ }^{17,19,21}$ In the present study, among ADHD patients using LAS and AAPs concomitantly, 39.74\% of the patients had a diagnosis of bipolar disorder, and $23.66 \%$ of the patients were diagnosed with psychosis and pervasive developmental disorders. These are the comorbidities for which use of AAPs is approved in children and adolescents. It is possible that these agents might be used with LAS for better management of ADHD or coexisting psychiatric conditions. However, odds of concomitant use were also high for psychiatric comorbidities, for which AAPs are not approved by the FDA, such as oppositional defiant disorder, personality disorders, and tics. It is possible that AAPs are being used off-label in ADHD patients. ${ }^{19,23}$ Given the high risk of metabolic and neurologic adverse effects associated with AAPs in children, there is a greater need for generating safety and efficacy data for concomitant use of LAS and AAPs in children. ${ }^{77,78}$ There is a treatment guideline for physicians regarding concomitant use for the treatment of schizophrenia in adolescents and adults. ${ }^{79} \mathrm{~A}$ well-defined guideline for concomitant use in ADHD children and adolescents can help clinicians. ${ }^{32,75,80}$

Mental illness severity has been found to be associated with the use of combination therapy in adults, ${ }^{63,81}$ but no such association has been reported in children and adolescents with ADHD. Although the direct relationship between ADHD 


\section{Predictors of Concomitant Use of Antipsychotics and Stimulants and Its Impact on Stimulant Persistence in Pediatric Attention Deficit Hyperactivity Disorder}

\section{TABLE 6 Determinants of Persistence of Index LAS in Children and Adolescents with ADHD}

\begin{tabular}{|c|c|c|c|c|c|}
\hline Characteristics & Adjusted HR & $\begin{array}{c}\text { 95\% CI for } \\
\text { Adjusted HR }\end{array}$ & Characteristics & Adjusted HR & $\begin{array}{c}\text { 95\% CI for } \\
\text { Adjusted HR }\end{array}$ \\
\hline \multicolumn{3}{|c|}{ Atypical antipsychotics } & \multicolumn{3}{|c|}{ Oppositional defiant disorder } \\
\hline Yes & $0.85^{\mathrm{a}}$ & $0.76-0.94$ & Yes & $0.79^{b}$ & $0.73-0.84$ \\
\hline No & Reference & - & No & Reference & - \\
\hline \multicolumn{3}{|l|}{ Sex } & \multicolumn{3}{|l|}{ Conduct disorder } \\
\hline Male & 0.98 & $0.95-1.01$ & Yes & $0.82^{b}$ & $0.77-0.88$ \\
\hline Female & Reference & - & No & Reference & - \\
\hline \multicolumn{3}{|l|}{ Age } & \multicolumn{3}{|c|}{ Learning disorders } \\
\hline $6-12$ & $0.74^{b}$ & $0.72-0.77$ & Yes & $0.87 \mathrm{c}$ & $0.80-0.94$ \\
\hline $13-16$ & Reference & - & No & Reference & - \\
\hline \multicolumn{3}{|l|}{ Health insurance } & \multicolumn{3}{|c|}{ Psychosis and pervasive developmental disorders } \\
\hline Private & 0.93 & $0.86-1.01$ & Yes & $0.72^{b}$ & $0.65-0.80$ \\
\hline Public & 1.11 & $0.99-1.24$ & No & Reference & - \\
\hline Other/unknown & Reference & - & \multicolumn{3}{|c|}{ Substance abuse and dependence disorders } \\
\hline \multicolumn{3}{|l|}{ Region } & Yes & $0.75^{b}$ & $0.64-0.86$ \\
\hline Midwest & $0.91^{\mathrm{b}}$ & $0.87-0.94$ & No & Reference & - \\
\hline South & $1.22^{\mathrm{b}}$ & $1.17-1.28$ & \multicolumn{3}{|l|}{ Enuresis } \\
\hline West & 0.99 & $0.93-1.04$ & Yes & $0.76^{\mathrm{b}}$ & $0.68-0.85$ \\
\hline East & Reference & - & No & Reference & - \\
\hline \multicolumn{3}{|l|}{ Year of entry } & \multicolumn{3}{|l|}{ Encopresis } \\
\hline 2005 & 1.00 & 0.96-1.04 & Yes & 0.84 & $0.68-1.03$ \\
\hline 2006 & 1.01 & $0.98-1.05$ & No & Reference & - \\
\hline 2004 & Reference & - & \multicolumn{3}{|l|}{ Tics } \\
\hline \multicolumn{3}{|c|}{ Season of index prescription } & Yes & 1.06 & $0.91-1.25$ \\
\hline $\begin{array}{l}\text { Spring } \\
\text { Summer }\end{array}$ & $\frac{1.00}{1.20^{\mathrm{b}}}$ & $\begin{array}{l}0.97-1.04 \\
1.15-1.25\end{array}$ & No & Reference & - \\
\hline Winter & $0.80^{\mathrm{b}}$ & $0.77-0.83$ & \multicolumn{3}{|l|}{ Comedications } \\
\hline Autumn & Reference & - & \multicolumn{3}{|l|}{ Nonstimulants } \\
\hline \multicolumn{3}{|c|}{ Physician specialty } & Yes & $0.62^{b}$ & $0.57-0.68$ \\
\hline Pediatrician & $0.96^{\mathrm{a}}$ & $0.94-0.98$ & No & Reference & - \\
\hline Psychiatrist & 1.05 & $1.00-1.10$ & \multicolumn{3}{|l|}{ Alpha 2-agonists } \\
\hline Other & Reference & - & Yes & $0.63^{b}$ & $0.58-0.68$ \\
\hline \multicolumn{3}{|l|}{ Comorbidities } & No & Reference & - \\
\hline \multicolumn{3}{|l|}{ Depression } & \multicolumn{3}{|l|}{ Antidepressants } \\
\hline Yes & $0.90^{\mathrm{b}}$ & $0.85-0.94$ & Yes & $0.71^{\mathrm{b}}$ & $0.67-0.75$ \\
\hline No & Reference & - & No & Reference & - \\
\hline Anxiety & & & Mood stabilizers & & \\
\hline Yes & $0.90^{\mathrm{a}}$ & $0.85-0.96$ & Yes & $0.64 \mathrm{~b}$ & $0.55-0.75$ \\
\hline No & Reference & - & No & Reference & - \\
\hline Bipolar disorder & & & Sedatives/hypnot & & \\
\hline Yes & 0.93 & $0.82-1.05$ & Yes & $0.54^{b}$ & $0.51-0.58$ \\
\hline No & Reference & - & No & Reference & - \\
\hline Oppositional con & & & Miscellaneous & & \\
\hline Yes & $0.76^{\mathrm{a}}$ & $0.64-0.90$ & Yes & $0.53^{a}$ & $0.33-0.84$ \\
\hline No & Reference & - & No & Reference & - \\
\hline Obsessive compu & sorder & & Recent mental he & ization & \\
\hline Yes & 1.01 & $0.79-1.29$ & Yes & $1.47^{\mathrm{b}}$ & $1.25-1.72$ \\
\hline No & Reference & - & No & Reference & - \\
\hline $\begin{array}{l}a P<0.01 \\
b P<0.0001 \\
{ }^{c} P<0.05 \\
A D H D=\text { attenti }\end{array}$ & & & & & \\
\hline
\end{tabular}


Cox model suggest that the use of AAPs had a positive impact on LAS treatment persistence. ADHD patients using AAPs were $15 \%$ more likely to be persistent on the index LAS treatment than AAPs nonusers. In contrast to the present finding, Sikirica et al. (2012) did not find any difference in the discontinuation rate of index stimulant between ADHD children treated with AAPs and non-antipsychotics. ${ }^{45}$ This could be due to difference in study population and other methodological differences. Concomitant use involving antipsychotic and stimulant medications might be needed to treat comorbid psychiatric and behavioral disorders, such as ADHD and disruptive behavioral disorders. ${ }^{82}$ Various international experts, including American Academy of Child \& Adolescent Psychiatry (AACP) and Texas Children's Medication Algorithm Project (CMAP), ${ }^{83}$ also support the concurrent use of antipsychotics and stimulants to treat ADHD children with comorbidities. ${ }^{75,80}$ However, a recently published systematic review found limited evidence regarding safety, efficacy, and tolerability for the concurrent use of AAPs and LAS. Future research is needed to compare benefits and risk of concomitant therapy with stimulant monotherapy. ${ }^{84}$

Consistent with previous literature, children were more likely to be persistent with index LAS treatment than adolescents. ${ }^{7,8,10,42,43,66,67}$ This could be due to the careful parental supervision of the administration of ADHD medications in young children. Adolescents, on the other hand, are more likely to make their own treatment decisions and may choose not to take medications. ${ }^{10,67,85}$ Additionally, hyperactive/impulsive adolescents might suffer from positive illusory bias, causing them to overrate their capabilities and underrate their problems relative to others. ${ }^{86}$ Among enabling factors, lower likelihood of persistence on the index LAS treatment during summer months needs special attention. ADHD youth were $20 \%$ less likely to be persistent in the use of index LAS medication during summer months than during autumn months. This observation is similar to the results of Cascade et al. (2008), who found a significant drop in total prescriptions for ADHD in the summer months. ${ }^{87}$ This possibly reflects symptomatic treatment of ADHD by physicians. Additionally, parents might not feel the need to medicate their children when they are out of school or on school break and consequently might discontinue the drug therapy during summer school holidays.

Among need factors, comorbidities, comedications, and recent mental health-related hospitalizations were positively associated with index LAS treatment persistence. As discussed already, AAPs might be used with LAS for better management of ADHD and coexisting psychiatric conditions. Optimal control of ADHD and associated comorbidities might translate into improved LAS persistence, as seen in the present study. This is further supported by the fact that there was a 29\%-47\% increase in index LAS treatment persistence when medications from other psychotropic drug class were added to the index LAS medication. Combination therapy is commonly used in ADHD patients to control ADHD symptoms and related comorbidities, manage improper response from monotherapy, help with sleep, and reduce side effects of a drug. ${ }^{16,28,88}$ Recent mental health hospitalization was associated with a higher risk of discontinuing the index LAS medication. This can be attributed to the complexity of these patients requiring constant treatment monitoring or suboptimal treatment effect in severe patients.

\section{Limitations}

The present study used a claims database, which offers several advantages, such as large sample size of privately insured patients, long follow-up period, and real-world clinical setting data. Prescription claims databases are valid and reliable sources for gathering medication therapy-related information and for measuring persistence of drug therapy. ${ }^{89-91}$ However, this study suffered from certain limitations. A 6-month baseline period without any pharmacy claim for any LAS was used to identify index cases of ADHD, but this criterion might include prevalent ADHD cases with extended drug holidays. Selection bias might be prevalent in the study, since the study population was not randomized to the concomitant use of LAS and AAPs. This study focused on those who initiated LAS only; therefore, the study population might be different from ADHD patients who used LAS along with IAS or SAS. The database used in the current study lacked information on patient characteristics such as race, education, and income. Previous literature suggests racial disparities in the concomitant use and persistence of psychotropic medications in ADHD children. ${ }^{7,8,43,66,73,92}$ Information on these variables would have provided a better understanding of the factors affecting concomitant use of LAS and AAPs and persistence of LAS medications. Future studies should investigate this matter using other databases. All the information was obtained from pharmacy and medical claims records, so it was not possible to determine the clinical conditions for which medications or concomitant therapy was used. Therefore, clinically appropriate concomitant therapy could not be distinguished from clinically inappropriate concomitant therapy.

Data on dispensed medication do not reflect that medication was actually taken. Additionally, patients might take medications outside the health insurance through out-of-pocket expenses. The definition of persistence used in the present study allowed a maximum refill gap of 30 days, which does not account for extended drug holidays such as summer school holidays. Thus, results from the present study provide a conservative estimate of LAS persistence in ADHD youth. This study did not distinguish between clinically appropriate treatment discontinuation and premature treatment discontinuation for reasons known to patients and caregivers, such as perceived need and lack of efficacy. It is possible that concomitant users are followed more closely by their prescribers and therefore do better with LAS persistence. Although it was beyond the scope of this study, this information would be helpful for developing interventions aimed at improving persistence of stimulant medications in ADHD children and adolescents. Information was missing on severity of mental health conditions. Although severity of mental illness was controlled by using mental health-related hospitalization, this information is usually underreported in medical claims. Thus, results obtained in 


\section{Predictors of Concomitant Use of Antipsychotics and Stimulants and Its Impact on Stimulant Persistence in Pediatric Attention Deficit Hyperactivity Disorder}

this study provide conservative estimates of the relationship between mental health severity, concomitant use of LAS and AAPs, and persistence. Generalizability of this study might be limited due to use of commercially insured children and adolescents with ADHD, which does not represent all of the children and adolescents with ADHD in the United States. Finally, age of the dataset used might be a limitation. Consequently, there is a need to replicate these study findings in other settings using more recent data.

\section{Conclusions}

Various predisposing, enabling, and need factors were associated with the concomitant use of LAS and AAPs and persistence to the index LAS medication. Likelihood of concomitant use of LAS and AAPs was high for approved and nonapproved indications among ADHD patients. Use of AAPs was positively associated with the persistence of index LAS medications. This could be attributed to control of behavioral symptoms of ADHD or comorbid symptomatology. It is possible that concomitant use of AAPs along with stimulants might help in better management of ADHD and its comorbid symptoms. Various randomized controlled trials and national and international organizations support the use of combination therapy for treating ADHD and coexisting comorbidities. However, there is limited evidence to support such use. More empirical evidence is needed for concomitant use of LAS and AAPs to see if the benefits of this practice outweigh the risks in the pediatric ADHD population.

\section{Authors}

VISHAL BALI, MS, PhD is Senior Health Outcomes Researcher, Engage2Health, Westlake Village, California; PRAVIN SHIVAJI KAMBLE, MS, PhD, is Research Scientist, Comprehensive Health Insights, Louisville, Kentucky; and RAJENDER R. APARASU, PhD, FAPhA, is Professor and Chair, Department of Pharmaceutical Health Outcomes and Policy, College of Pharmacy, University of Houston, Texas.

AUTHOR CORRESPONDENCE: Rajender R. Aparasu, PhD, FAPhA, Dept. of Pharmaceutical Health Outcomes and Policy, University of Houston College of Pharmacy, 1441 Moursund St., Houston, TX 77030. Tel.: 832.842.8374; Fax: 832.842.8383;

E-mail: rraparasu@uh.edu.

\section{REFERENCES}

1. Centers for Disease Control and Prevention. Increasing prevalence of parent-reported attention-deficit/hyperactivity disorder among children-United States, 2003 and 2007. MMWR Morb Mortal Wkly Rep. 2010;59(44):1439-43.

2. Bloom B, Cohen RA, Freeman G. Summary health statistics for U.S. children: National Health Interview Survey, 2009. Vital Health Stat 10. 2010(247):1-82

3. Willcutt EG. The prevalence of DSM-IV attention-deficit/hyperactivity disorder: a meta-analytic review. Neurotherapeutics. 2012;9(3):490-99.

4. Wolraich M, Brown L, Brown RT, et al. ADHD: clinical practice guideline for the diagnosis, evaluation, and treatment of attention-deficit/hyperactivity disorder in children and adolescents. Pediatrics. 2011;128(5):1007-22.

5. Stahl SM. Mechanism of action of stimulants in attention-deficit/hyperactivity disorder. J Clin Psychiatry. 2010;71(1):12-13.

6. Yanofski J. The dopamine dilemma: using stimulants and antipsychotics concurrently. Psychiatry (Edgmont). 2010;7(6):18-23

7. Lawson KA, Johnsrud M, Hodgkins P, Sasané R, Crismon ML. Utilization patterns of stimulants in ADHD in the medicaid population: a retrospective analysis of data from the Texas Medicaid program. Clin Ther. 2012;34(4):944-56

8. Palli SR, Kamble PS, Chen H, Aparasu RR. Persistence of stimulants in children and adolescents with attention-deficit/hyperactivity disorder. J Child Adolesc Psychopharmacol. 2012;22(2):139-48.

9. Christensen L, Sasané R, Hodgkins P, Harley C, Tetali S. Pharmacological treatment patterns among patients with attention-deficit/hyperactivity disorder: retrospective claims-based analysis of a managed care population. Curr Med Res Opin. 2010;26(4):977-89.

10. Sanchez RJ, Crismon ML, Barner JC, Bettinger T, Wilson JP. Assessment of adherence measures with different stimulants among children and adolescents. Pharmacotherapy. 2005;25(7):909-17.

11. Cascade E, Kalali AH, Weisler RH. Short-acting versus long-acting medications for the treatment of ADHD. Psychiatry (Edgmont). 2008;5(8):24-27.

12. Kemner JE, Lage MJ. Impact of methylphenidate formulation on treatment patterns and hospitalizations: a retrospective analysis. Ann Gen Psychiatry. 2006;5:5

13. Lage M, Hwang P. Effect of methylphenidate formulation for attention deficit hyperactivity disorder on patterns and outcomes of treatment. J Child Adolesc Psychopharmacol. 2004;14(4):575-81

14. Pliszka S; AACAP Work Group on Quality Issues. Practice parameter for the assessment and treatment of children and adolescents with attentiondeficit/hyperactivity disorder. J Am Acad Child Adolesc Psychiatry. 2007;46(7):894-921.

15. Perrin JM, Stein MT, Amler RW, et al. Clinical practice guideline: treatment of the school-aged child with attention-deficit/hyperactivity disorder. Pediatrics. 2001;108(4):1033-44.

16. Comer JS, Olfson M, Mojtabai R. National trends in child and adolescent psychotropic polypharmacy in office-based practice, 1996-2007. J Am Acad Child Adolesc Psychiatry. 2010;49(10):1001-10.

17. Zito JM, Safer DJ, DosReis S, Magder LS, Gardner JF, Zarin DA. Psychotherapeutic medication patterns for youths with attention-deficit/ hyperactivity disorder. Arch Pediatr Adolesc Med. 1999;153(12):1257-63.

18. Miller R. Mechanisms of action of antipsychotic drugs of different classes, refractoriness to therapeutic effects of classical neuroleptics, and individual variation in sensitivity to their actions: Part I. Curr Neuropharmacol. 2009;7(4):302-14.

19. Crystal S, Olfson M, Huang C, Pincus H, Gerhard T. Broadened use of atypical antipsychotics: safety, effectiveness, and policy challenges. Health Aff (Millwood). 2009;28(5):w770-81. 


\section{Predictors of Concomitant Use of Antipsychotics and Stimulants and Its Impact on Stimulant Persistence in Pediatric Attention Deficit Hyperactivity Disorder}

20. Christian R, Saavedra L, Gaynes BN, et al. Appendix A, Tables of FDAApproved Indications for First- and Second-Generation Antipsychotics. In: Future research needs for first- and second-generation antipsychotics for children and young adults. Future Research Needs Paper No. 13. (Prepared by the RTI-UNC Evidence-based Practice Center under Contract No. 290200710056 I). Rockville, MD: Agency for Healthcare Research and Quality; February 2012. Available at: http://www.ncbi.nlm.nih.gov/books/ NBK84656/. Accessed April 3, 2015.

21. John M. Eisenberg Center for Clinical Decisions and Communications Science. First-generation versus second-generation antipsychotics in adults: comparative effectiveness. April 10, 2013 In: Comparative Effectiveness Review Summary Guides for Clinicians [Internet]. Rockville, MD: Agency for Healthcare Research and Quality; 2007. Available at: http://www.ncbi. nlm.nih.gov/books/NBK142851/. Accessed March 16, 2015.

22. Cooper WO, Hickson GB, Fuchs C, Arbogast PG, Ray WA. New users of antipsychotic medications among children enrolled in TennCare. Arch Pediatr Adolesc Med. 2004;158(8):753-59.

23. Zito JM, Derivan AT, Kratochvil CJ, Safer DJ, Fegert JM, Greenhill LL. Off-label psychopharmacologic prescribing for children: history supports close clinical monitoring. Child Adolesc Psychiatry Ment Health. 2008;2(1):24.

24. Fullerton CA, Epstein AM, Frank RG, Normand SL, Fu CX, McGuire TG. Medication use and spending trends among children with ADHD in Florida's Medicaid program, 1996-2005. Psychiatr Serv. 2012;63(2):115-21.

25. Olfson M, Blanco C, Liu SM, Wang S, Correll CU. National trends in the office-based treatment of children, adolescents, and adults with antipsychotics. Arch Gen Psychiatry. 2012;69(12):1247-56.

26. Penzner JB, Dudas M, Saito E, et al. Lack of effect of stimulant combination with second-generation antipsychotics on weight gain, metabolic changes, prolactin levels, and sedation in youth with clinically relevant aggression or oppositionality. J Child Adolesc Psychopharmacol. 2009;19(5):563-73.

27. Weiss M, Panagiotopoulos C, Giles L, et al. A naturalistic study of predictors and risks of atypical antipsychotic use in an attention-deficit/hyperactivity disorder clinic. J Child Adolesc Psychopharmacol. 2009;19(5):575-82.

28. Maglione M, Maher A, Hu J, et al. Off-label use of atypical antipsychotics: an update. Comparative Effectiveness Review No. 43. (Prepared by the Southern California/RAND Evidence-based Practice Center under Contract No. HHSA290-2007-10062-1.) AHRQ Publication No. 11-EHC087-EF. Rockville, MD: Agency for Healthcare Research and Quality. September 2011. Available at: http://effectivehealthcare.ahrq.gov/ehc/products/150/786/ CER43_Off-LabelAntipsychotics_execsumm_20110928.pdf. Accessed March 16, 2015.

29. Correll CU, Penzner JB, Parikh UH, et al. Recognizing and monitoring adverse events of second-generation antipsychotics in children and adolescents. Child Adolesc Psychiatr Clin N Am. 2006;15(1):177-206.

30. Seida JC, Schouten JR, Boylan K, et al. Antipsychotics for children and young adults: a comparative effectiveness review. Pediatrics. 2012;129(3):e771-84.

31. Betts KA, Sikirica V, Hodgkins P, et al. Period prevalence of concomitant psychotropic medication usage among children and adolescents with attention-deficit/hyperactivity disorder during 2009. J Child Adolesc Psychopharmacol. 2014;24(5):260-68.

32. Sikirica V, Fridman M, Bruno A, Hodgkins P, Erder MH. Concomitant pharmacotherapy of psychotropic medications in EU children and adolescents with attention-deficit/hyperactivity disorder. Drugs $R D$. 2013;13(4):271-80.

33. Felt BT, Biermann B, Christner JG, Kochhar P, Harrison RV. Diagnosis and management of ADHD in children. Am Fam Physician. 2014;90(7):456-64.

34. Atzori P, Usala T, Carucci S, Danjou F, Zuddas A. Predictive factors for persistent use and compliance of immediate-release methylphenidate: a 36-month naturalistic study. J Child Adolesc Psychopharmacol. 2009;19(6):673-81.
35. Perwien A, Hall J, Swensen A, Swindle R. Stimulant treatment patterns and compliance in children and adults with newly treated attention-deficit/ hyperactivity disorder. J Manag Care Pharm. 2004;10(2):122-29. Available at: http://www.amcp.org/data/jmcp/Research-122-129.pdf.

36. Barkley RA, McMurray MB, Edelbrock CS, Robbins K. Side effects of methylphenidate in children with attention deficit hyperactivity disorder: a systemic, placebo-controlled evaluation. Pediatrics. 1990;86(2):184-92.

37. McBride MC. An individual double-blind crossover trial for assessing methylphenidate response in children with attention deficit disorder. J Pediatr. 1988;113(1 Pt 1):137-45.

38. Charles L, Schain R. A four-year follow-up study of the effects of methylphenidate on the behavior and academic achievement of hyperactive children. J Abnorm Child Psychol. 1981;9(4):495-505.

39. Jensen PS, Arnold LE, Swanson JM, et al. 3-year follow-up of the NIMH MTA study. J Am Acad Child Adolesc Psychiatry. 2007;46(8):989-1002.

40. Charach A, Ickowicz A, Schachar R. Stimulant treatment over five years: adherence, effectiveness, and adverse effects. J Am Acad Child Adolesc Psychiatry. 2004:43(5):559-67.

41. Firestone P. Factors associated with children's adherence to stimulant medication. Am J Orthopsychiatry. 1982;52(3):447-57.

42. Marcus SC, Wan GJ, Kemner JE, Olfson M. Continuity of methylphenidate treatment for attention-deficit/hyperactivity disorder. Arch Pediatr Adolesc Med. 2005;159(6):572-78.

43. Winterstein AG, Gerhard T, Shuster J, et al. Utilization of pharmacologic treatment in youths with attention deficit/hyperactivity disorder in Medicaid database. Ann Pharmacother. 2008;42(1):24-31.

44. Yanofski J. The dopamine dilemma-part II: could stimulants cause tolerance, dependence, and paradoxical decompensation? Innov Clin Neurosci. 2011;8(1):47-53.

45. Sikirica V, Pliszka SR, Betts KA, et al. Comparative treatment patterns, resource utilization, and costs in stimulant-treated children with ADHD who require subsequent pharmacotherapy with atypical antipsychotics versus non-antipsychotics. J Manag Care Pharm. 2012;18(9):676-89. Available at: http://www.amcp.org/WorkArea/DownloadAsset.aspx?id=15872.

46. IMS LifeLink. LifeLink Health Plan Claims Database: overview and study design issues. April 26, 2010. Available at: http://www.uams.edu/ TRI/hsrcore/Lifelink_Health_Plan_Claims_Data_DesignIssues_wcost_ April2010[1].pdf. Accessed March 16, 2015.

47. Olfson M, Marcus S, Wan G. Stimulant dosing for children with ADHD: a medical claims analysis. J Am Acad Child Adolesc Psychiatry. 2009;48(1):51-59.

48. Winterstein AG, Gerhard T, Shuster J, Saidi A. Cardiac safety of methylphenidate versus amphetamine salts in the treatment of ADHD. Pediatrics. 2009;124(1):e75-80.

49. Ray WA. Evaluating medication effects outside of clinical trials: newuser designs. Am J Epidemiol. 2003;158(9):915-20.

50. National Institute of Mental Health. Attention deficit hyperactivity disorder (ADHD). U.S. Department of Health and Human Services, National Institutes of Health. NIH Publication No. 08-3572. Revised 2008. Available at: https://education.ucsb.edu/sites/default/files/hosford_clinic/docs/adhd_ booklet.pdf. Accessed March 16, 2015.

51. Kotzan JA, Maclean R, Wade W, et al. Prevalence and patterns of concomitant use of selective serotonin reuptake inhibitors and other antidepressants in a high-cost polypharmacy cohort. Clin Ther. 2002;24(2):237-48.

52. Cramer JA, Roy A, Burrell A, et al. Medication compliance and persistence: terminology and definitions. Value Health. 2008;11(1):44-47.

53. Andersen R, Newman JF. Societal and individual determinants of medical care utilization in the United States. Milbank Mem Fund 2 Health Soc. 1973;51(1):95-124.

54. Kamble P, Chen H, Sherer J, Aparasu RR. Antipsychotic drug use among elderly nursing home residents in the United States. Am J Geriatr Pharmacother. 2008;6(4):187-97. 


\section{Predictors of Concomitant Use of Antipsychotics and Stimulants and Its Impact on Stimulant Persistence in Pediatric Attention Deficit Hyperactivity Disorder}

55. Kamble P, Chen H, Sherer JT, Aparasu RR. Use of antipsychotics among elderly nursing home residents with dementia in the U.S.: an analysis of National Survey Data. Drugs Aging. 2009;26(6):483-92.

56. Kamble P, Sherer J, Chen H, Aparasu R. Off-label use of second-generation antipsychotic agents among elderly nursing home residents. Psychiatr Serv. 2010;61(2):130-36.

57. Chen CY, Gerhard T, Winterstein AG. Determinants of initial pharmacological treatment for youths with attention-deficit/hyperactivity disorder. J Child Adolesc Psychopharmacol. 2009;19(2):187-95.

58. Chen CY, Yeh HH, Chen KH, Chang IS, Wu ECH, Lin KM. Differential effects of predictors on methylphenidate initiation and discontinuation among young people with newly diagnosed attention-deficit/hyperactivity disorder. J Child Adolesc Psychopharmacol. 2011;21(3):265-73

59. Pliszka SR. Psychiatric comorbidities in children with attention deficit hyperactivity disorder. Pediatric Drugs. 2003;5(11):741-50.

60. Radigan M, Lannon P, Roohan P, Gesten F. Medication patterns for attention-deficit/hyperactivity disorder and comorbid psychiatric conditions in a low-income population. J Child Adolesc Psychopharmacol. 2005;15(1):44-56.

61. Waxmonsky J. Assessment and treatment of attention deficit hyperactivity disorder in children with comorbid psychiatric illness. Curr Opin Pediatr. 2003;15(5):476-82.

62. Boles M, Lynch FL, DeBar LL. Variations in pharmacotherapy for attention deficit hyperactivity disorder in managed care. J Child Adolesc Psychopharmacol. 2001;11(1):43-52.

63. Morrato EH, Dodd S, Oderda G, Haxby DG, Allen R, Valuck RJ Prevalence, utilization patterns, and predictors of antipsychotic polypharmacy: experience in a multistate Medicaid population, 1998-2003. Clin Ther 2007;29(1):183-95.

64. Winterstein AG, Gerhard T, Shuster J, Johnson M, Zito JM, Saidi A Cardiac safety of central nervous system stimulants in children and adolescents with attention-deficit/hyperactivity disorder. Pediatrics. 2007;120(6):e1494-501.

65. Leslie SR, Gwadry-Sridhar F, Thiebaud P, Patel BV. Calculating medication compliance, adherence and persistence in administrative pharmacy claims databases. Pharm Programming. 2008;1(1):13-19.

66. Chacko A, Newcorn JH, Feirsen N, Uderman JZ. Improving medication adherence in chronic pediatric health conditions: a focus on ADHD in youth. Curr Pharm Des. 2010;16(22):2416-23.

67. Miller AR, Lalonde CE, McGrail KM. Children's persistence with methylphenidate therapy: a population-based study. Can J Psychiatry. 2004;49(11):761-68

68. Fulton B, Scheffler R, Hinshaw S, et al. National variation of ADHD diagnostic prevalence and medication use: health care providers and education policies. Psychiatr Serv. 2009;60(8):1075-83.

69. Cox ER, Motheral BR, Henderson RR, Mager D. Geographic variation in the prevalence of stimulant medication use among children 5 to 14 years old: results from a commercially insured U.S. sample. Pediatrics. 2003;111(2):237-43.

70. Pohl GM, Van Brunt DL, Ye W, Stoops WW, Johnston JA. A retrospective claims analysis of combination therapy in the treatment of adult attentiondeficit/hyperactivity disorder (ADHD). BMC Health Serv Res. 2009;9:95.

71. Jeste DV, Blazer D, Casey D, et al. ACNP White Paper: update on use of antipsychotic drugs in elderly persons with dementia. Neuropsychopharmacology. 2008;33(5):957-70.

72. U.S. Food and Drug Administration. Public health advisory: deaths with antipsychotics in elderly patients with behavioral disturbances. April 11, 2005. Available at: http://www.fda.gov/drugs/drugsafety/postmarketdrugsafetyinformationforpatientsandproviders/ucm053171. Accessed March 16, 2015.

73. Mojtabai R, Olfson M. National trends in psychotropic medication polypharmacy in office-based psychiatry. Arch Gen Psychiatry. 2010;67(1):26-36.
74. Larson K, Russ SA, Kahn RS, Halfon N. Patterns of comorbidity, functioning, and service use for U.S. children with ADHD, 2007. Pediatrics, 2011;127(3):462-70

75. Spencer TJ, Biederman J, Mick E. Attention-deficit/hyperactivity disorder: diagnosis, lifespan, comorbidities, and neurobiology. J Pediatr Psychol. 2007;32(6):631-42.

76. Kendall T, Taylor E, Perez A, Taylor C. Diagnosis and management of attention-deficit/hyperactivity disorder in children, young people, and adults: summary of NICE guidance. BMJ. 2008;337:al239.

77. Ben Amor L. Antipsychotics in pediatric and adolescent patients: a review of comparative safety data. J Affect Disord. 2012;138(Suppl):S22-30.

78. Cohen D, Bonnot O, Bodeau N, Consoli A, Laurent C. Adverse effects of second-generation antipsychotics in children and adolescents: a Bayesian meta-analysis. J Clin Psychopharmacol. 2012;32(3):309-16.

79. Lehman AF, Lieberman JA, Dixon LB, et al. Practice guideline for the treatment of patients with schizophrenia, second edition. Am J Psychiatry. 2004;161(2 Suppl):1-56.

80. Pliszka SR, Crismon M, Hughes CW, et al. The Texas Children's Medication Algorithm Project: revision of the algorithm for pharmacotherapy of attention-deficit/hyperactivity disorder. J Am Acad Child Adolesc Psychiatry. 2006;45(6):642-57.

81. Ganguly R, Kotzan JA, Miller LS, Kennedy K, Martin BC. Prevalence, trends, and factors associated with antipsychotic polypharmacy among Medicaid-eligible schizophrenia patients, 1998-2000. J Clin Psychiatry. 2004;65(10): 1377-88

82. Patel NC, Sallee FR. What's the best treatment for comorbid ADHD/ bipolar mania? Curr Psychiatry. 2005;4(4):27-37.

83. Kutcher S, Aman M, Brooks SJ, et al. International consensus statement on attention-deficit/hyperactivity disorder (ADHD) and disruptive behaviour disorders (DBDs): clinical implications and treatment practice suggestions. Eur Neuropsychopharmacol. 2004;14(1):11-28.

84. Linton D, Barr AM, Honer WG, Procyshyn RM. Antipsychotic and psychostimulant drug combination therapy in attention deficit/hyperactivity and disruptive behavior disorders: a systematic review of efficacy and tolerability. Curr Psychiatry Rep. 2013;15(5):355.

85. Meaux JB, Hester C, Smith B, Shoptaw A. Stimulant medications: a trade-off? The lived experience of adolescents with ADHD. J Spec Pediatr Nurs. 2006;11(4):214-26.

86. Owens JS, Goldfine ME, Evangelista NM, Hoza B, Kaiser NM. A critical review of self-perceptions and the positive illusory bias in children with ADHD. Clin Child Fam Psychol Rev. 2007;10(4):335-51.

87. Cascade E, Kalali AH, Weisler RH, Lenderts S. Seasonality and the changing adult/child prescription ratios in ADHD therapy. Psychiatry (Edgmont). 2008;5(1):23-25.

88. Bussing R, Winterstein AG. Polypharmacy in attention deficit hyperactivity disorder treatment: current status, challenges and next steps. Curr Psychiatry Rep. 2012;14(5):447-49.

89. Kirking DM, Ammann MA, Harrington CA. Comparison of medical records and prescription claims files in documenting prescription medication therapy. J Pharmacoepidemiol. 1996;5(1):3-15.

90. Tamblyn R, Lavoie G, Petrella L, Monette J. The use of prescription claims databases in pharmacoepidemiological research: the accuracy and comprehensiveness of the prescription claims database in Quebec. J Clin Epidemiol. 1995;48(8):999-1009.

91. Dezii CM. Persistence with drug therapy: a practical approach using administrative claims data. Manag Care. 2001;10(2):42-45.

92. Martin A, Van Hoof T, Stubbe D, Sherwin T, Scahill L. Multiple psychotropic pharmacotherapy among child and adolescent enrollees in Connecticut Medicaid managed care. Psychiatr Serv. 2003;54(1):72-77. 